OPEN ACCESS

Edited by:

Hajo Dieringa,

Helmholtz Centre for Materials and Coastal Research (HZG), Germany

Reviewed by:

Chamini Mendis,

Brunel University London,

United Kingdom

Mingyi Zheng,

Harbin Institute of Technology, China

*Correspondence:

E. Abe

abe@material.t.u-tokyo.ac.jp

Specialty section:

This article was submitted to

Structural Materials,

a section of the journal

Frontiers in Materials

Received: 13 August 2019 Accepted: 14 October 2019

Published: 30 October 2019

Citation:

Egusa D, Kawaguchi K and Abe E

(2019) Direct Observations of Precursor Short-Range Order Clusters of Solute Atoms in a LPSO-Forming

Mg-Zn-Gd Ternary Alloy.

Front. Mater. 6:266

doi: 10.3389/fmats.2019.00266

\section{Direct Observations of Precursor Short-Range Order Clusters of Solute Atoms in a LPSO-Forming Mg-Zn-Gd Ternary Alloy}

\author{
D. Egusa ${ }^{1}$, K. Kawaguchi ${ }^{1}$ and E. Abe ${ }^{1,2 *}$ \\ ${ }^{1}$ Department of Materials Science and Engineering, University of Tokyo, Tokyo, Japan, ${ }^{2}$ Research Center for Structural \\ Materials, National Institute for Materials Science, Tsukuba, Japan
}

We have investigated short-range order (SRO) clusters of solute atoms in a $\mathrm{Mg}_{97} \mathrm{Zn}_{1} \mathrm{Gd}_{2}$ alloy which forms a long-period stacking/order (LPSO) phase, based on aberration-corrected scanning transmission electron microscopy (STEM) observations and first-principles calculations. High-angle annular dark-field (HAADF) STEM provides directly the individual $\mathrm{Gd}$ atom positions through significant atomic-number dependent Z-contrast, and their averaged image-processing have immediately shown up the representative SRO-Gd configurations being in favor of the second-nearest networks in the hcp-Mg structure. Interestingly, Zn atoms seem to be essentially placed at the particular sites within the SRO-Gd configurations to form $\mathrm{DO}_{19}$-like $\mathrm{ZnGd}_{3}$ clusters, a validity of which are verified by STEM image simulations and first-principles calculations. These $\mathrm{DO}_{19}$-like $\mathrm{ZnGd}_{3}$ clusters in the $h c p-\mathrm{Mg}$ matrix are likely to be a precursor sub-structure to the $\mathrm{L}_{2}$-type $\mathrm{Zn}_{6} \mathrm{Gd} \mathrm{d}_{8}$ clusters that are embedded in the local fcc layers in the LPSO structure. In fact, we find that these $\mathrm{DO}_{19}$-like $\mathrm{ZnGd}_{3}$ clusters seem to form a layered atmosphere prior to the LPSO formation, providing an important clue on how the LPSO phases nucleate and grow.

Keywords: Mg alloys, long-period stacking/order (LPSO) phase, solute clusters, scanning transmission electron microscopy, first-principles calculations

\section{INTRODUCTION}

Since Mg has the lowest density among practical metals, it is expected to use for transportation equipment such as aircraft and automobiles for improving their energy efficiency (Egami et al., under review). Owing to a low strength and a poor ductility of $\mathrm{Mg}$, it is practically alloyed with a trace amount of additive elements. Rare earth elements (hereinafter denoted as RE) have been known as one of the effective alloying elements that significantly improve the mechanical properties of Mg alloys (Homma et al., 2009; Nie, 2012; Sandlöbes et al., 2014), which are originated from such as the texture weakening by solute segregations or the age hardening due to fine precipitations of the Mg-RE compounds. However, adding a large amount of RE impairs the lightness of Mg alloys, so many studies have been conducted on alloy designs with a limited amount of RE additions.

In recent years, $\mathrm{Mg}$ alloys with a small addition of RE and transition metals (TM) have attracted wide attentions because they exhibit excellent mechanical properties (Kawamura et al., 2001; Itoi et al., 2004; Yamasaki et al., 2005; Honma et al., 2007; Kawamura and Yamasaki, 2007; Hagihara et al., 2010). In these ternary alloys, various kinds of precipitates form depending on the additive 
elements and the heat-treatment conditions (Honma et al., 2005; Matsushita et al., 2016; Fujita et al., 2018; Gu et al., 2018; Koizumi et al., 2018). In particular, Mg-Zn-RE ternary alloys have been focused as one of the candidates for next-generation lightweight alloys, which indeed show excellent mechanical properties due to the presence of the long period stacking/order (LPSO) phase (Abe et al., 2002, 2011; Kawamura and Yamasaki, 2007; Zhu et al., 2010; Egusa and Abe, 2012; Kim and Kawamura, 2013; Saal and Wolverton, 2014; Egami and Abe, 2015; Yamashita et al., 2019) as a strengthening phase via kink deformation (Kawamura and Yamasaki, 2007; Homma et al., 2009; Shao et al., 2010; Egusa et al., 2013; Yamasaki et al., 2013; Xu et al., 2015; Garcés et al., 2018; Hagihara et al., 2019; Inamura, 2019). The LPSO structures consist of stacking order as well as chemical order with respect to the hexagonal close-packed ( $h c p$ ) $\mathrm{Mg}$ structure. A distinctive structural-unit represented by Intrinsic-II type stacking faults $\left(I_{2}-\mathrm{SF}\right)$ forms a local face-centered cubic $(f c c)$ stacking environment, in which the additive $\mathrm{Zn} / \mathrm{RE}$ elements are commonly distributed (Abe et al., 2002, 2011). The soluteenriched $\mathrm{I}_{2}$-SF (SESF: solute-enriched stacking fault) is a basicunit of the LPSO phases, and the isolated SESFs can be distributed randomly in the hcp-Mg matrix (Yamasaki et al., 2007; Nie et al., 2008; Egami et al., under review). In addition, further analysis on the LPSO structure showed that $\mathrm{Zn}$ and RE are ordered to form the $\mathrm{L}_{2}$-type cluster embedded within the $f c c$-SESF (Yokobayashi et al., 2011; Egusa and Abe, 2012; Ma et al., 2013; Saal and Wolverton, 2014; Okuda et al., 2015; Hosokawa et al., 2018; Nishioka et al., 2018), which indeed plays an important role for increasing thermodynamic stability of the SESF (Egami et al., under review).

It is known that these $\mathrm{Mg}-\mathrm{Zn}-\mathrm{RE}$ systems are classified into Type $\mathrm{I}(\mathrm{RE}=\mathrm{Y}, \mathrm{Dy}, \mathrm{Ho}, \mathrm{Er}, \mathrm{Tm})$ and Type II $(\mathrm{RE}=\mathrm{Gd}, \mathrm{Tb})$ according to formation of the LPSO phase during solidifications or aging processes (Kawamura and Yamasaki, 2007). Mg-Zn-Gd alloys, classified into Type II, precipitate the LPSO phase during an isothermal annealing, whose behaviors were experimentally summarized as a timetemperature-transformation (TTT) diagram (Yamasaki et al., 2007). Solute-enriched platelet zones (Guinier-Preston like zone) are formed at relatively low temperatures $(<\sim 500 \mathrm{~K})$ (Nishijima et al., 2008; Saito et al., 2011; Koizumi et al., 2018). On the other hand, the LPSO phase and SESFs are formed in the $\alpha-\mathrm{Mg}$ matrix at relatively high temperature (Jono et al., 2013; Gröbner et al., 2015). It should be noted here that $\mathrm{Zn}$ is essential for the formation of these various precipitates/zones, which have never been available for the Mg-Gd binary alloys (He et al., 2006; Nishijima and Hiraga, 2007).

Clustering of solute elements and the introduction of the $I_{2}-\mathrm{SF}$ are essential events for formation of the LPSO structure. Recent studies have suggested two possible formation processes of the LPSO structures; one driven by the introduction of the $I_{2}-\mathrm{SF}$, and the other driven by spinodal-like phase separation which involves clustering of solute atoms (Yamamoto et al., 2013; Umebayashi et al., 2014; Okuda et al., 2015, 2017; Egami et al., under review). Okuda et al. investigated precipitation processes of the LPSO phase from the amorphous $\mathrm{Mg}-\mathrm{Zn}-\mathrm{RE}$ alloys in the quenched ribbon sample by in-situ synchrotron X-ray observations (Okuda et al., 2017). They reported that there is a short-range order
(SRO) of solute element at the initial stage of the LPSO phase formation, whose sizes are corresponding to about a solute dimer in the amorphous state, and they grow in the crystalline hcp-Mg state. Photoemission spectroscopy investigations also supported formation of the solute SRO clusters at the initial stage of the LPSO phase formation, suggesting that the SRO is a precursor phenomenon to form the $\mathrm{L}_{2}$-type clusters (Hosokawa et al., 2018). Such precursor phenomenon significantly affects on the thermodynamics of the LPSO phase formation; however, the detailed structures and spatial distributions of such SRO clusters are not clarified yet. In the present study, we investigate the precursor SRO clusters in the hcp-matrix of a $\mathrm{Mg}-\mathrm{Zn}$ Gd alloy based on direct observations using advanced electron microscopy, and discuss their detailed structures and spatial distributions in terms of the LPSO phase formation.

\section{MATERIALS AND METHODS}

A nominal composition of the alloy used in the present study was $\mathrm{Mg}_{97} \mathrm{Zn}_{1} \mathrm{Gd}_{2}$ (at. \%). Master alloy ingots were prepared by high frequency induction melting of pure metals in an argon atmosphere. In order to control ordering and distributions of the SESF, the alloy ingots were solution treated at $793 \mathrm{~K}$ for $2 \mathrm{~h}$, followed by water quench, and then annealed at $573 \mathrm{~K}$ for $10 \mathrm{~h}$ (Yamasaki et al., 2007). All the heat treatments were performed using a Pyrex tube in an argon atmosphere after evacuation to pressures lower than $3 \times 10^{-3} \mathrm{~Pa}$. Microstructures of the samples were observed by scanning electron microscopy (SEM, JEM-7900F) using backscattering electron (BSE) detector at the accelerating voltage of $15 \mathrm{kV}$. For atomic-resolution high-angle annular dark-field (HAADF)-scanning transmission electron microscopy (STEM) observations, we used an aberration-corrected $200 \mathrm{kV}$ STEM (JEM-ARM200F) that provides a minimum probe of $\sim 0.8 \AA$ with a convergence semi-angle of $22 \mathrm{mrad}$. For HAADF imaging, the annular detector was set to collect the electrons scattered at angles higher than $90 \mathrm{mrad}$, which is sufficiently high to reveal a chemical sensitive Z-contrast. Thin foils for STEM observations were prepared by standard Ar-ion milling. Image simulations were carried out using the xHREM software based on the fast-Fourier-transform multi-slice algorithm (Ishizuka, 2002). First-principles calculations were performed to evaluate formation energies of the $h c p-\mathrm{Mg}$ crystals containing solute atoms. The super cell size for calculations was $5 \times 5 \times 4$ with respect to the primitive hcp-Mg structure, containing 200 atoms. Structural optimizations were performed by using the Vienna Ab initio Simulation Package (VASP) code within the framework of density-functional theory (Kresse and Furthmüller, 1996), based on generalized gradient approximation (Perdew et al., 1992), and ultrasoft scalar relativistic pseudo-potentials (detailed conditions for calculations are described in the Figure 4 captions).

\section{RESULTS}

Figure 1a shows a SEM-BSE image obtained from a heattreated $\mathrm{Mg}_{97} \mathrm{Zn}_{1} \mathrm{Gd}_{2}$ alloy. Bright-contrast regions in the image 


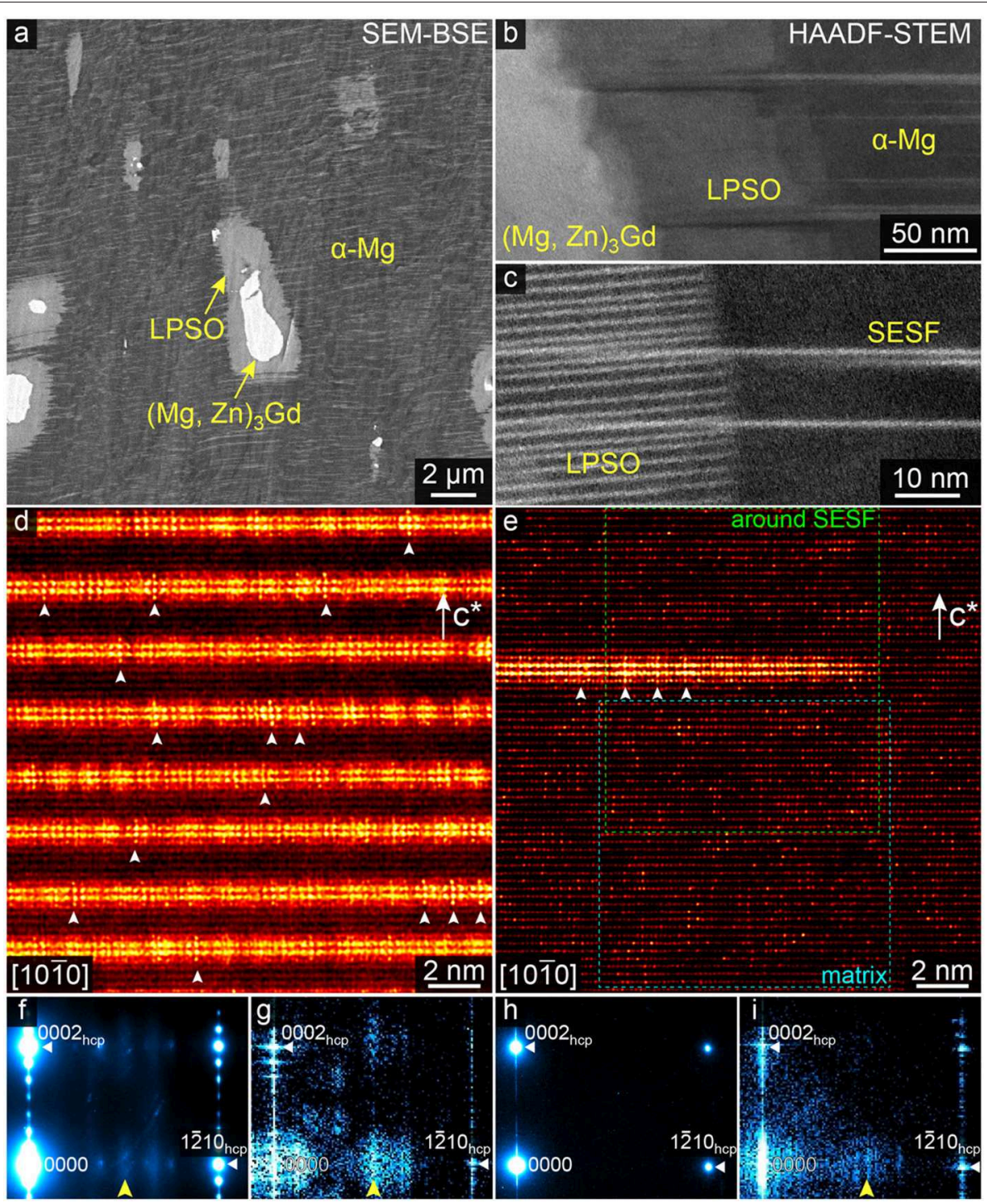

FIGURE 1 | (a) SEM-BSE image taken from a heat-treated $\mathrm{Mg}_{97} \mathrm{Zn}_{1} \mathrm{Gd}_{2}$ alloy. (b,c) HAADF-STEM images of the multiple-phase coexisting regions of the (Mg,Zn) ${ }_{3}$ Gd compound, the LPSO phase and the $\alpha$-Mg phase with essential SESFs. (d,e) Atomic-resolution HAADF-STEM images of the 14 H-type LPSO phase and the $\alpha$-Mg matrix along the $[10 \overline{1} 0]_{\text {hcp }}$ directions, respectively. $c^{*}$ denotes the $c$-axis of the matrix crystals. Blue and green dotted rectangles in (e) correspond to the enlarged areas shown in Figures 3a, 7a, respectively. (f) EDP and (g) PS calculated from the LPSO phase images of (d), and (h,i) represent those for the $\alpha$-Mg matrix image of (e) in the same manner, respectively. The indices of the major reflections in EDPs and PSs are given based on the hcp-Mg structure.

correspond to the (Mg, $\mathrm{Zn})_{3} \mathrm{Gd}$ compound and the LPSO phase, as denoted in the image. The $(\mathrm{Mg}, \mathrm{Zn})_{3} \mathrm{Gd}$ compound does not fully dissolve and remains even after the solution-treatment (Jono et al., 2013). The (Mg, $\mathrm{Zn})_{3} \mathrm{Gd}$ compounds are surrounded by the LPSO phases, suggesting that the LPSO phase has formed from the $\mathrm{Zn} / \mathrm{Gd}$-rich compound during the heat-treatment. In addition, a large number of thin bright lines in the $\alpha$-Mg matrix can be seen clearly, which correspond to the SESF and/or very fine platelet LPSO precipitates. Figure $\mathbf{1 b}$ shows a HAADFSTEM image obtained around the $(\mathrm{Mg}, \mathrm{Zn})_{3} \mathrm{Gd}$ compound and the LPSO phase. The LPSO phase is continuously formed from the $(\mathrm{Mg}, \mathrm{Zn})_{3} \mathrm{Gd}$ compound, and the SESFs are grown from the edge of the LPSO phase, as clearly seen in Figure 1c. We below investigate details of solute arrangements in the $\alpha-\mathrm{Mg}$ matrix.

Figures 1d,e show HAADF-STEM images of the 14H-type LPSO phase and the $\alpha-M g$ matrix, taken along the $[10 \overline{1} 0]_{\text {hcp }}$ directions. The corresponding electron diffraction patterns (EDP) and the power spectra (PS) of the images of Figures 1d,e are shown in Figures $\mathbf{1 f}-\mathbf{i}$, respectively. HAADF imaging provides a significant atomic-number dependent contrast, so that bright dots in the images represent the $\mathrm{Zn}$ and/or Gd enriched atomic columns. White arrowheads in the LPSO structure image of Figure 1d indicate characteristic bright-dot configurations representing the $\mathrm{L1}_{2}$-type $\mathrm{Zn}_{6} \mathrm{Gd}_{8}$ clusters, which are successfully 

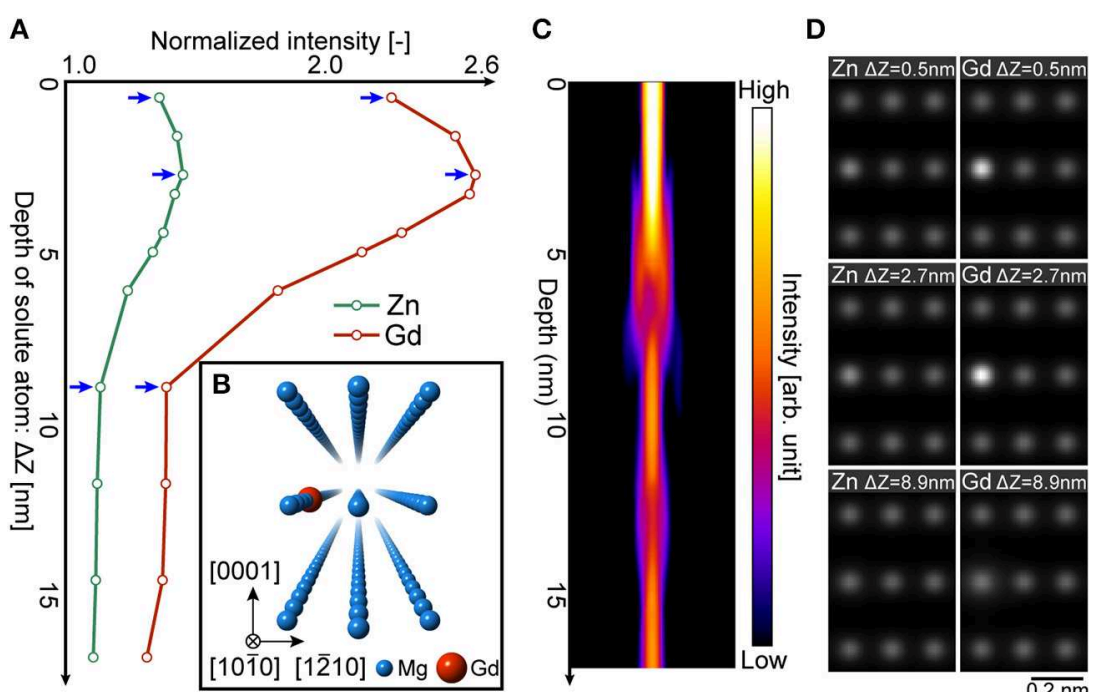

FIGURE 2 | (A) Simulated HAADF-intensity profiles of the Mg atomic columns containing single solute atom, showing solute depth-position dependent change; green and red profiles for $\mathrm{Zn}$ and $\mathrm{Gd}$, respectively. The simulations are performed for the $h c p-\mathrm{Mg}$ crystal projected along [1010] drawn in (B), where the single $\mathrm{Zn}$ or Gd atom is placed at the left-middle column with a certain depth position. Simulation conditions are; spherical aberration coefficient Cs $=0 \mathrm{~mm}$, specimen thickness $=16.8 \mathrm{~nm}$, defocus $=0 \mathrm{~nm}$, beam-convergent semi-angle $\alpha=22 \mathrm{mrad}$. (C) Incident electron-beam propagation along the $[10 \overline{10}]_{h c p}$ direction of the hcp-Mg crystal, calculated with the above conditions. (D) Representative simulated HAADF images for the different solute Zn/Gd depth positions, each of which corresponds to the depth at those indicated by arrows in (A).

imaged in the $[10 \overline{1} 0]_{\text {hcp }}$ projection. The $\mathrm{L1}_{2}-\mathrm{Zn}_{6} \mathrm{Gd}_{8}$ clusters can be arrayed in an ordered manner within the SESF (i.e., inplane order) due to inter-cluster interactions (Kimizuka et al., 2014; Yamasaki et al., 2014; Yamashita et al., 2019). For the present LPSO phase, the number of weak peaks between 0000 and $1 \overline{2} 10$ reflections in the EDP (Figure 1f) indicates $6 \times$ (1210) order in average. In addition, note that weak diffuse peak appears in the corresponding PS (Figure 1g) as indicated by the arrowhead, representing the $\mathrm{Zn} / \mathrm{Gd}$ SRO due to presence of the $\mathrm{L}_{2}$-type clusters. The diffuse peak is not obvious in the EDP but significantly enhanced in the PS, since the latter has been reconstructed from the HAADF image whose information is highly weighted to heavy-atom configurations (i.e., highly sensitive to the SRO structures composed of heavy atoms).

By looking the image of Figure 1e, there also appears the characteristic $\mathrm{L}_{2}$-type SRO contrast within the SESF such as indicated by arrowheads, suggesting the $\mathrm{L}_{2}$-type cluster formation even in the isolated SESF (Egami et al., under review). Note that there are no significant peaks between 0000 and $1 \overline{2} 10$ in the DP (Figure 1h), but there indeed appears a diffuse peak in the PS (Figure 1i), as indicated by the arrowhead. This is again due to a significant atomic-number weighted Z-contrast of the HAADF imaging, which is able to enhance largely the hidden heavy-atom structures if any. Therefore, the solute SRO cluster formation can be highly anticipated within the $\alpha-\mathrm{Mg}$ matrix, details of which will be discussed later.

In order to clarify the solute SRO structures, we first attempt simulations on how the single $\mathrm{Zn} / \mathrm{Gd}$ atoms in the $\alpha-\mathrm{Mg}$ matrix are imaged by an aberration-corrected HAADFSTEM. Figure 2A shows simulated HAADF-intensity profiles constructed by varying a depth position of the single solute atom in the atomic column, as schematically drawn in Figure 2B. Simulations are performed for the $h c p-\mathrm{Mg}$ crystal projected along the $[10 \overline{1} 0]_{\mathrm{hcp}}$, and the specimen thickness is set to be $16.8 \mathrm{~nm}$ based on electron-energy-loss spectroscopy (EELS) logratio measurements (Malis et al., 1988). The image intensity is normalized with respect to that of the pure $\mathrm{Mg}$ atomic column. Both for the $\mathrm{Zn}$ and Gd atoms, the intensity profiles show the highest values when the solute atom is located at the depth of $2.7 \mathrm{~nm}$ from the surface, and the intensity becomes almost constant when the solute atoms are located beyond the depth of $8.9 \mathrm{~nm}$. Figure 2C shows the focused electron-beam channeling behaviors propagated along the $[10 \overline{1} 0]_{\text {hcp }}$ direction in the $h c p-\mathrm{Mg}$ crystal. Due to dynamical diffraction effects with a wide convergence angle of the modern aberrationcorrected STEM, the beam intensity exhibits a certain maximum at a few nanometers below the surface and oscillates along the propagating direction (Mittal and Mkhoyan, 2011). By comparing the intensity profiles (Figure 2A) and the beam propagations (Figure 2C), it immediately turns out that the column intensities show their maxima when the solute atoms are placed at the depth position relevant to the beam-flux maximum. Therefore, the column-intensity variations in the $h c p$ $\mathrm{Mg}$ matrix (e.g., see Figure 1d) are governed by the individual solute atoms placed at a certain depth range. Figure 2D shows the representative simulated images with the solute atoms placed at $0.5,2.7$, and $8.9 \mathrm{~nm}$ in depth positions, respectively, which correspond to those indicated by blue arrows in Figure $2 \mathrm{~A}$. Again, the column intensities are sufficiently strong when the solute atoms are located at the depth near the surface, and become hardly distinguishable when the solute atoms are at the deeper positions. Since the composition of the present 


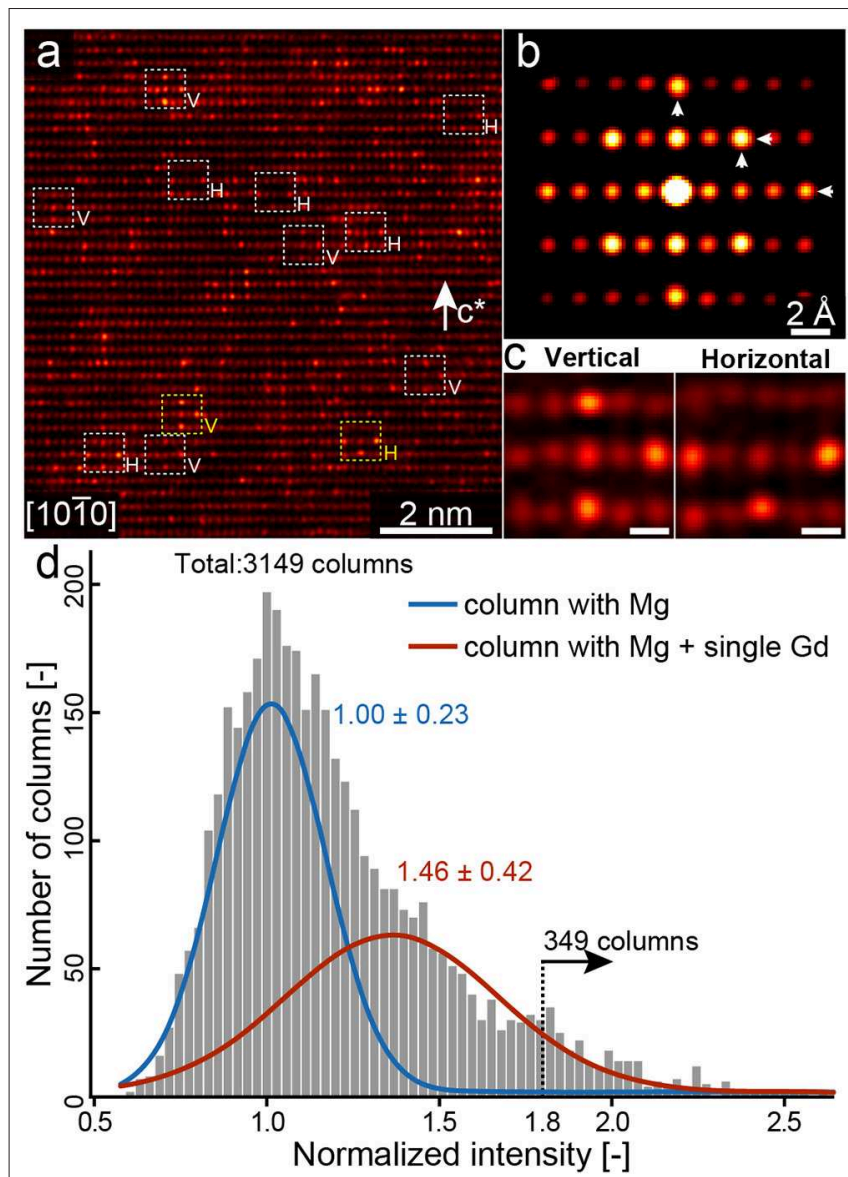

FIGURE 3 | (a) Enlarged HAADF-STEM image of the blue-box region in Figure 1d. $c^{\star}$ denotes the $c$-axis of the matrix hcp crystal. (b) Auto-correlation pattern obtained from the image of (a). (c) Representative local STEM images showing characteristic bright-dot arrangements, which are enlargements of those indicated by yellow dashed squares in (a), being with scale bars of $2 \AA$ By using yellow-square regions as the references, the similar contrast regions indicated by white dashed squares have been selected according to cross-correlation evaluations. Details are described in the text. (d) Intensity distributions of the atomic columns in the image of (a). Total number of the columns measured is 3,149 . Blue and red lines represent gauss-fitting results; mean values, and standard deviations for each fitted-profile are $1.00 \pm 0.23$ and $1.46 \pm 0.42$, respectively.

hcp-Mg matrix is sufficiently dilute (Mg-0.3at.\%Zn-0.8at.\%Gd by SEM-EDS analysis), we assume that there is almost no plurality of solute atoms in the same atomic column for a thin specimen $(\sim 17.0 \mathrm{~nm}$ for the present case), leading that the column intensities higher than 1.8 are likely to represent the single $\mathrm{Gd}$ atoms in the $h c p-\mathrm{Mg}$ matrix (i.e., individual single $\mathrm{Gd}$ atoms placed at the depth up to $6.1 \mathrm{~nm}$ are detected in the experiment).

Figure 3a shows a HAADF-STEM image obtained from the $\alpha$ $\mathrm{Mg}$ matrix at the position indicated by the dotted blue-rectangle in Figure 1e. Intensity variations at each of the columns in the image directly represent the distribution of individual solute atoms, as governed mostly by Gd atoms. Figure $\mathbf{3 b}$ shows an auto-correlation pattern constructed from Figure 3a, reflecting the spatial correlation of the bright dots in the STEM image. The strong spots indicated by white arrowheads suggest directly the SRO correlations by the solute atoms, corresponding to the second- and/or third-nearest neighbor atomic sites projected along [1210] direction. Note that there are some characteristic configurations of the bright dots, such as indicated by the dotted rectangles in Figure 3a (see the figure caption for the yellow/white representations). Figure $3 c$ exemplifies the two typical configurations, denoted as "vertical" and "horizontal," whose details will be discussed later. In order to evaluate the column-intensity distributions, we have extracted the intensity of the individual atomic columns and applied gaussian fitting. Figure 3d shows the intensity distribution measured from 3,149 atomic columns in the $\alpha-\mathrm{Mg}$ matrix image. As demonstrated in Figure 2A, the normalized intensity of the $\mathrm{Zn}$-containing column appears about 1.2 at the highest, suggesting that $\mathrm{Zn}$ distributions can hardly be distinguished solely by HAADF intensity. Therefore, the intensity distributions are supposed to be two groups, i.e., the most columns are with pure $\mathrm{Mg}$ and containing single Gd atom. The red and blue profiles in Figure 3d correspond to the gaussian-fitted results of the column intensity distributions, respectively. Based on the fitted result with the reasonably high $\mathrm{R}$-square value of 0.987 , the average intensity of the columns containing single Gd atom is estimated as 1.46 with respect to the pure $\mathrm{Mg}$ columns, the value of which fairly matches to the image simulations (Figure 2). According to the above analysis, the number of columns with the intensity higher than 1.8 turns out to be 349 , which is about $11 \%$ for the total number of the measured atomic columns $(3,149)$. The intensity level of 1.8 is relevant to the single Gd atom located up to the depth of $6.1 \mathrm{~nm}$ from the surface; i.e., single $\mathrm{Gd}$ atom per $10 \mathrm{Mg}$ atoms can be roughly estimated based on the $h c p-\mathrm{Mg}$ crystal in the $[10 \overline{1} 0]_{\mathrm{hcp}}$ projection (see Figure 2). Therefore, the solute Gd fraction in the $\alpha-\mathrm{Mg}$ matrix is derived as being about 1.1 at.\% (11\%/10), which is not largely deviated from the estimated matrix composition (0.8at.\%Gd by SEM-EDS analysis) and hence support the validity of imaging individual Gd atoms.

\section{DISCUSSION}

Presence of the SRO clusters is directly indicated by STEM observations, as shown in Figure 3c. Here, we investigate possible SRO structures by comparing formation energies of various $\mathrm{Gd}$ atom arrangements using first-principles calculations. Figure 4A shows a model for placing two Gd atoms in the $h c p-M g$ structure. Position of the first Gd atom is fixed at the center of the polyhedron represented by orange planes, and the second Gd atom is placed at the positions denoted by capital letters from $\mathrm{A}$ to $\mathrm{H}$. Figure $4 \mathrm{~B}$ shows the calculated formation energies for the two Gd atom configurations. Energy base-line is set to the one calculated when the Gd atoms are sufficiently separated (apart more than $1 \mathrm{~nm}$ ) and hence their interactions can be sufficiently negligible. The lowest formation energy is obtained when the second $\mathrm{Gd}$ atom is placed at the $\mathrm{C}$ site, whose configuration is inserted in Figure 4B. Two Gd and four $\mathrm{Mg}$ are located at the octahedral sites, and the Gd-Gd configuration corresponds to the 

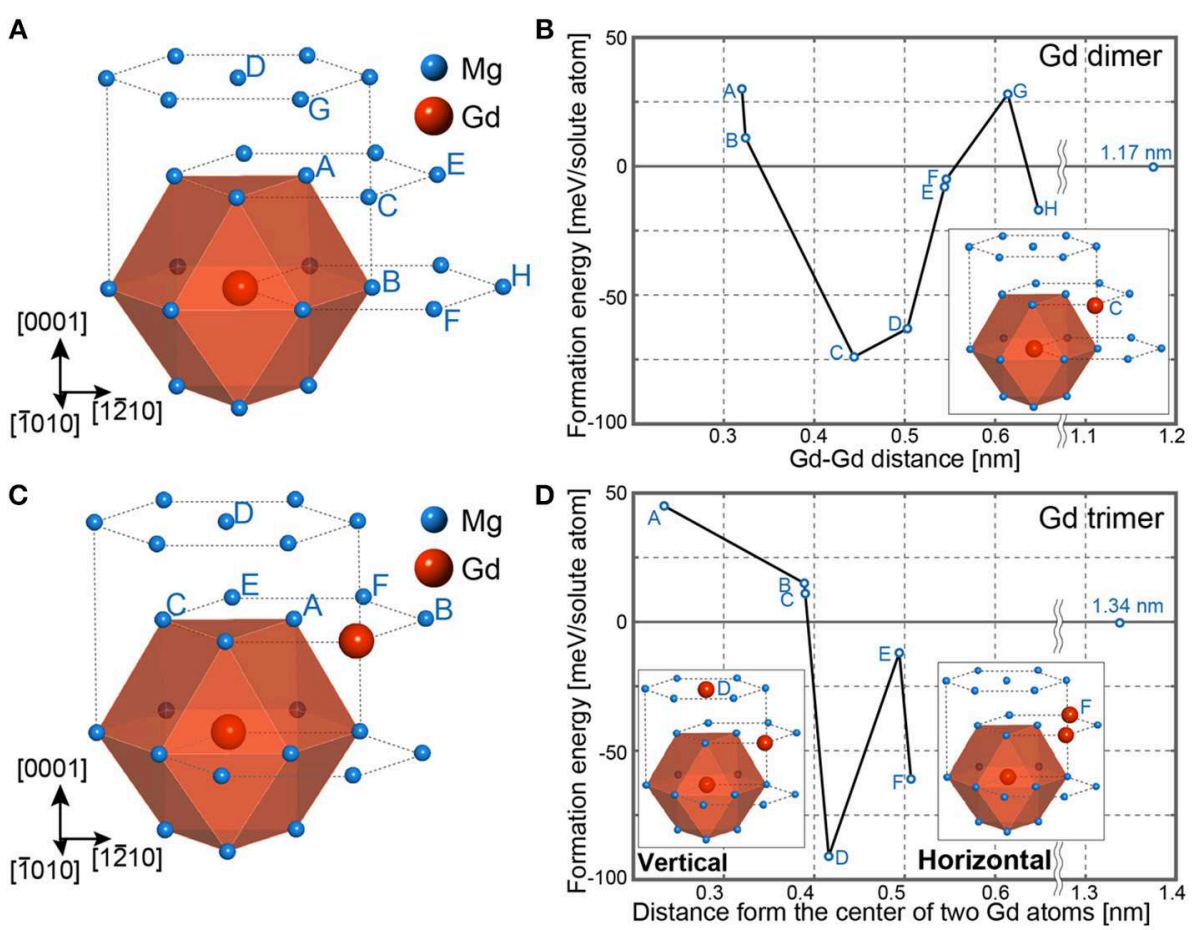

FIGURE 4 | First-principles calculations of the $\mathbf{G d}(\mathbf{A}, \mathbf{B})$ dimer and $\mathbf{( C , D )}$ trimer embedded in the hcp-Mg structure. Calculations were made with a hcp-base $5 \times 5 \times$ 4 supercell containing 200 atoms. Atom positions used for the second and the third Gd atoms are denoted by capital letters in (A,C), respectively. Calculated formation energies of the $\mathrm{Gd}(\mathbf{B})$ dimer and (D) trimer at the each position in (A,C), respectively. For the both cases, representative energy-minimized Gd configurations are inserted. For computations, the cut-off energy is chosen as $350 \mathrm{eV}$, with a $3 \times 3 \times 3 \mathrm{k}$-mesh. Calculations are performed by non-fixed conditions both for atomic positions and a unit-cell volume.

second-nearest neighbor in the hcp-Mg structure. Note that the second-nearest neighbor RE arrangements represents a partial structure of a $\mathrm{D}_{19}$-type order, which is commonly observed in various $\mathrm{Mg}$ - RE compounds (Nie, 2012). We termed the pair of these Gd configurations as "dimer" hereafter. In fact, dimer RE configurations appear to be frequent in the observed STEM image (Figure 3); though, further extended SRO configurations, such as indicated in Figure 3c, turn out to be also prominent in the present alloy.

Figure 4C shows a model for placing triple Gd atoms in the $h c p-\mathrm{Mg}$ structure, in which two Gd atoms are already fixed at the stable dimer environments, and the third Gd is placed at the positions denoted from A to F. Figure 4D shows calculated formation energies of the models. The energy-base is also set when the Gd atoms are sufficiently separated (more than $1 \mathrm{~nm}$ ) in the super cell. There are two positions that give local minima for the formation energy, D and F, whose Gd arrangements are inserted in Figure 4D. We termed these Gd configurations as "vertical trimer $\left(\mathrm{T}_{\mathrm{V}}\right)$ " and "horizontal trimer

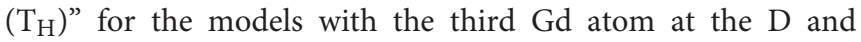
F sites, respectively (note that the "D" site already appears as an energetically favorable position during dimer considerations; namely, the simultaneous $\mathrm{Gd}$ atoms both at the $\mathrm{C}$ and $\mathrm{D}$ sites in Figure $4 \mathrm{~B}$ provide the $\mathrm{Tv}$ configuration). For the both trimers, the third Gd atom to the dimer is placed at the second-nearest neighbor to the other Gd atoms. It should be noted here that the Gd configurations in $\mathrm{T}_{\mathrm{V}}$ and $\mathrm{T}_{\mathrm{H}}$ are relevant to the brightdot arrangements those frequently observed in Figure 3a, as indicated by dashed squares denoted with $\mathrm{V}$ and $\mathrm{H}$, respectively. Also, the bright-dot appearances in the auto-correlation pattern (Figure 3b) can be explained by these two types of the Gd trimer, $\mathrm{T}_{\mathrm{V}}$ and $\mathrm{T}_{\mathrm{H}}$, supporting that these trimer configurations are representative solute-atom SRO clusters in the $\alpha-\mathrm{Mg}$ matrix. For the present $\mathrm{Mg}-\mathrm{Zn}-\mathrm{Gd}$ ternary alloys, it is anticipated that the $\mathrm{T}_{\mathrm{V}} / \mathrm{T}_{\mathrm{H}}$ SRO clusters intrinsically accompany the $\mathrm{Zn}$ atoms, and hence we further examine the possible $\mathrm{Zn}$ positions that are energetically favored within the Gd trimmers.

Figure 5A shows the models placing a single $\mathrm{Zn}$ atom within the $\mathrm{Gd}$ trimer structures $\left(\mathrm{T}_{\mathrm{V}}\right.$ and $\mathrm{T}_{\mathrm{H}}$ ), and the formation energies calculated for each of the $\mathrm{Zn}$ positions are summarized in Figure 5B. For the both $\mathrm{T}_{\mathrm{V}}$ and $\mathrm{T}_{\mathrm{H}}$, the $\mathrm{Zn}$ at the A sites appear to be the lowest formation energies with a significant energy gain about 398 and $447 \mathrm{meV} /$ cell, respectively. Note that the $\mathrm{Zn}$ at the A sites show the energy differences larger than $100 \mathrm{meV} /$ cell even compared with the next energetically-favored B sites, indicating that the $\mathrm{Zn}$ atoms at the A sites significantly stabilize the $\mathrm{T}_{\mathrm{V}} / \mathrm{T}_{\mathrm{H}}$ structures. Hereafter, we denote these $\mathrm{T}_{\mathrm{V}} / \mathrm{T}_{\mathrm{H}}$ SRO configurations of $\mathrm{Zn} / \mathrm{Gd}$ atoms as a $\mathrm{D}_{19}$-like $\mathrm{ZnGd}_{3}$ cluster. It should be noted that the atomic positions in the $\mathrm{ZnGd}_{3}$ cluster are relaxed from the ideal $h c p-\mathrm{Mg}$ structure; average Gd-Gd interatomic distances in the $\mathrm{T}_{\mathrm{V}}$ - and $\mathrm{T}_{\mathrm{H}}-\mathrm{ZnGd}_{3}$ clusters are estimated to be 4.40 and $4.46 \AA$, respectively, which are smaller than the relevant distance 


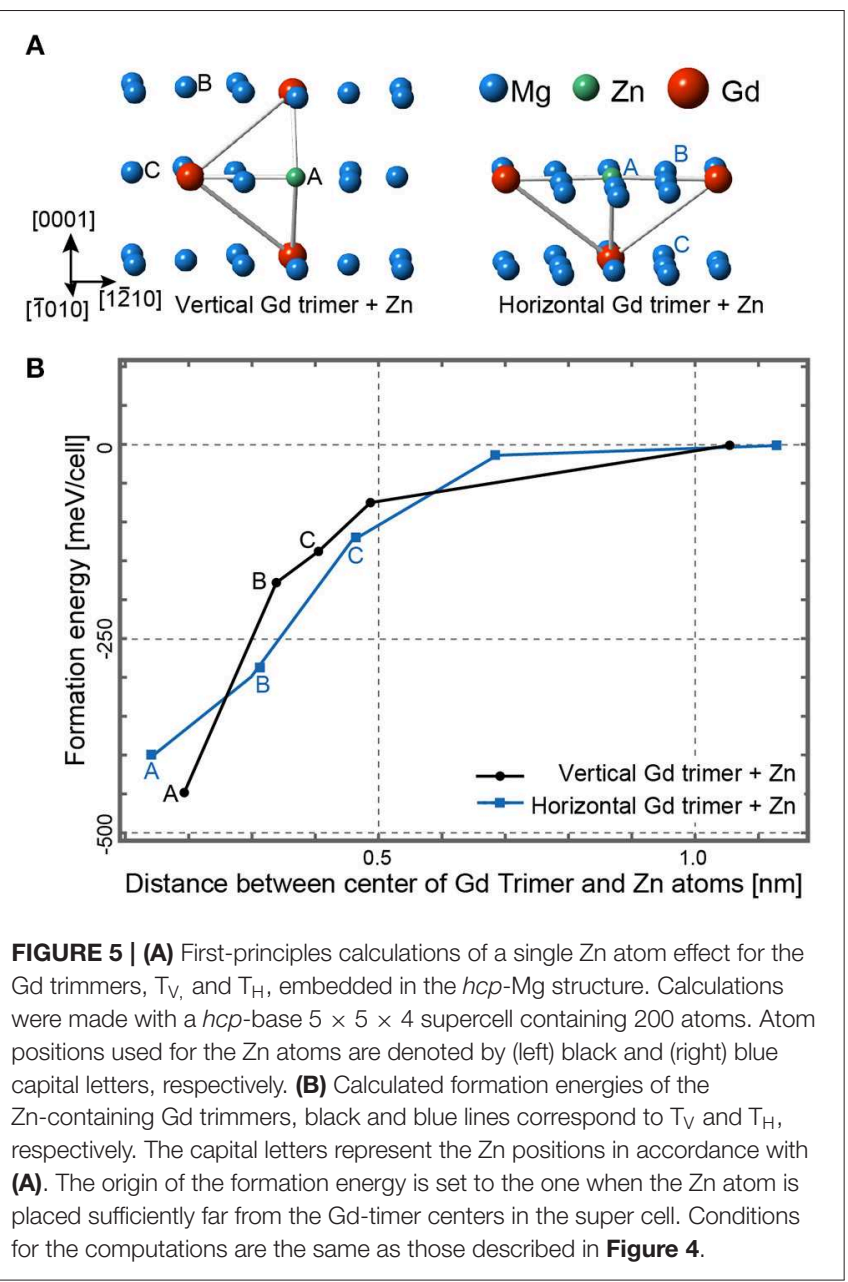

of $4.50 \AA$ in the ideal $h c p-\mathrm{Mg}$ structure. It is worth mentioning here that, for the LPSO phase, the Gd-Gd interatomic distance in the $\mathrm{L}_{2}$-type $\mathrm{Zn}_{6} \mathrm{Gd}_{8}$ cluster becomes $3.93 \AA$, being significantly shorter than that of the present $\mathrm{ZnGd}_{3}$ clusters. This is perhaps originated from the strong condensations between the $\mathrm{Zn} / \mathrm{Gd}$ atoms, causing significant relaxations whose displacements are likely to depend on a total number of the constituent solute atoms in the clusters.

The presence of the $\mathrm{D}_{19}$-like $\mathrm{ZnGd}_{3}$ clusters can be verified from the local intensity analysis of the HAADF-STEM images. Figure 6A shows the experimental and the simulated images of the $\mathrm{T}_{\mathrm{V}}-\mathrm{ZnGd}_{3}$ SRO clusters. The experimental image is an averaged one that has been reconstructed by searching automatically the similar $\mathrm{T}_{\mathrm{V}}$-SRO contrast regions over the image (Figure 3a), according to the cross-correlation evaluation of the local contrast variations; e.g., as shown in Figure 3a, given yellow-square regions as the references, the similar contrast regions of white dashed squares have been selected (templatematching, see for details the supplement in Egami and Abe, 2015). Note that the $\mathrm{T}_{\mathrm{V}}$-SRO cluster has three variants and differently appear in the $\langle 1 \overline{2} 10\rangle$ projections, and hence the extracted image of Figure 6A represents one of the variants. The image simulations are performed for the $\mathrm{T}_{\mathrm{V}}-\mathrm{Gd}_{3}$ (Figure $4 \mathrm{D}$ ) and the
$\mathrm{T}_{\mathrm{V}}-\mathrm{ZnGd}_{3}$ (Figure $\mathbf{5 A}$ ), whose intensity profiles are taken across the $\mathrm{X}-\mathrm{Y}$ direction of each image and compared with that of the corresponding experiment image, as shown in Figure 6B. It is evident that the $\mathrm{T}_{\mathrm{V}}$-cluster with $\mathrm{Zn}$ provides significantly better fit to the observed intensity, confirming that the present $\mathrm{T}_{\mathrm{V}}$-SRO clusters are essentially a ternary $\mathrm{ZnGd}_{3}$. We should also note that the slight peak-shift of the Gd position is also reproduced fairly well by the simulation with the $\mathrm{Zn}$ atom, as indicated by an arrowhead, supporting strongly the presence of the $\mathrm{Zn}$ atom that causes relaxation for the $\mathrm{T}_{\mathrm{V}}-\mathrm{Gd}_{3}$ configurations and provides a considerable energy gain (Figure 5B). Figures $6 \mathrm{C}$, D show a series of analysis for the $\mathrm{T}_{\mathrm{H}}$-type $\mathrm{SRO}$ cluster, as being made along with the same manner for the $\mathrm{T}_{\mathrm{V}}$-type SRO cluster described above. The experimental profiles are also reproduced significantly better by the simulation with the $\mathrm{Zn}$-containing cluster, confirming that the $\mathrm{T}_{\mathrm{H}}$-type $\mathrm{SRO}$ cluster also forms as a ternary $\mathrm{ZnGd}_{3}$.

Now that the SRO- $\mathrm{ZnGd}_{3}$ clusters appear to be a $\mathrm{D}_{19^{-}}$ like configuration, which prompts the notion about structural similarity with the $\mathrm{L1}_{2}$-type $\mathrm{Zn}_{6} \mathrm{Gd}_{8}$ cluster in the LPSO phase. In the both clusters, Gd atoms are placed at the second-nearest neighbor in the original $h c p-\mathrm{Mg}$ sites or the local $f c c$ environment sites in the intrinsic-II type stacking fault (Egusa and Abe, 2012), and $\mathrm{Zn}$ occupies the first-nearest neighbor to these Gd atoms. This similarity in local structures supports an idea that the $\mathrm{D} 0_{19^{-}}$like $\mathrm{ZnGd}_{3}$ cluster can be a precursor to the $\mathrm{L}_{2}$-type $\mathrm{SRO}$ cluster. To complete the transformation, the $\mathrm{D}_{19}$-like $\mathrm{ZnGd}_{3}$ clusters more than two are necessary to aggregate to form the $\mathrm{L}_{2}$-type $\mathrm{Zn}_{6} \mathrm{Gd}_{8}$ cluster, and the process must accompany the local $h c p$ $f c c$ stacking change. With this in mind, we here focus on the spatial distribution of the $\mathrm{ZnGd}_{3}$ clusters in the $\alpha-\mathrm{Mg}$ matrix. Figure 7a shows an enlarged HAADF-STEM image of Figure 1d (green-rectangle region), where the single SESF is formed in the $\alpha-\mathrm{Mg}$ matrix. A large number of bright spots clearly show up in the image, some of which indeed represent the $\mathrm{ZnGd}_{3}$ clusters as described before. By carefully looking at the image, the bright spots seem to not distribute uniformly but form weak layered atmosphere. By tracing the entire intensity profile along the $c$-axis, as shown in Figure $\mathbf{7 b}$, weak local maxima indeed appear at the positions indicated by arrowheads. Interestingly, these positions are at the distance from 7 or 14 atomic layers from the SESF, whose modulation length is equivalent to the $c$-axis correlation of the $14 \mathrm{H}$-LPSO structure. As confirmed by the STEM image of the relevant region taken along the [12110] direction (Figure 7c), there is no change in the stacking sequences except for the single SESF. Therefore, the observed intensity modulations imply that the $\mathrm{D}_{19}$-like $\mathrm{ZnGd}_{3}$ clusters form a layered solute atmosphere in the $h c p-\mathrm{Mg}$ matrix around the SESF, being prior to the introduction of stacking faults into the hcp-Mg matrix (similar phenomena was also reported for the Mg-Al-Gd system; Kishida et al., 2013). It should be noted here that the layered-atmosphere modulation across the $c$-axis is extended longer than a nanometer-scale, which may require long-range solute interactions significantly longer than those for the short-range clusters. At present, it is difficult to clarify the origin of such long-range correlations based on first-principle calculations with a limited number of solute atoms. The origin 

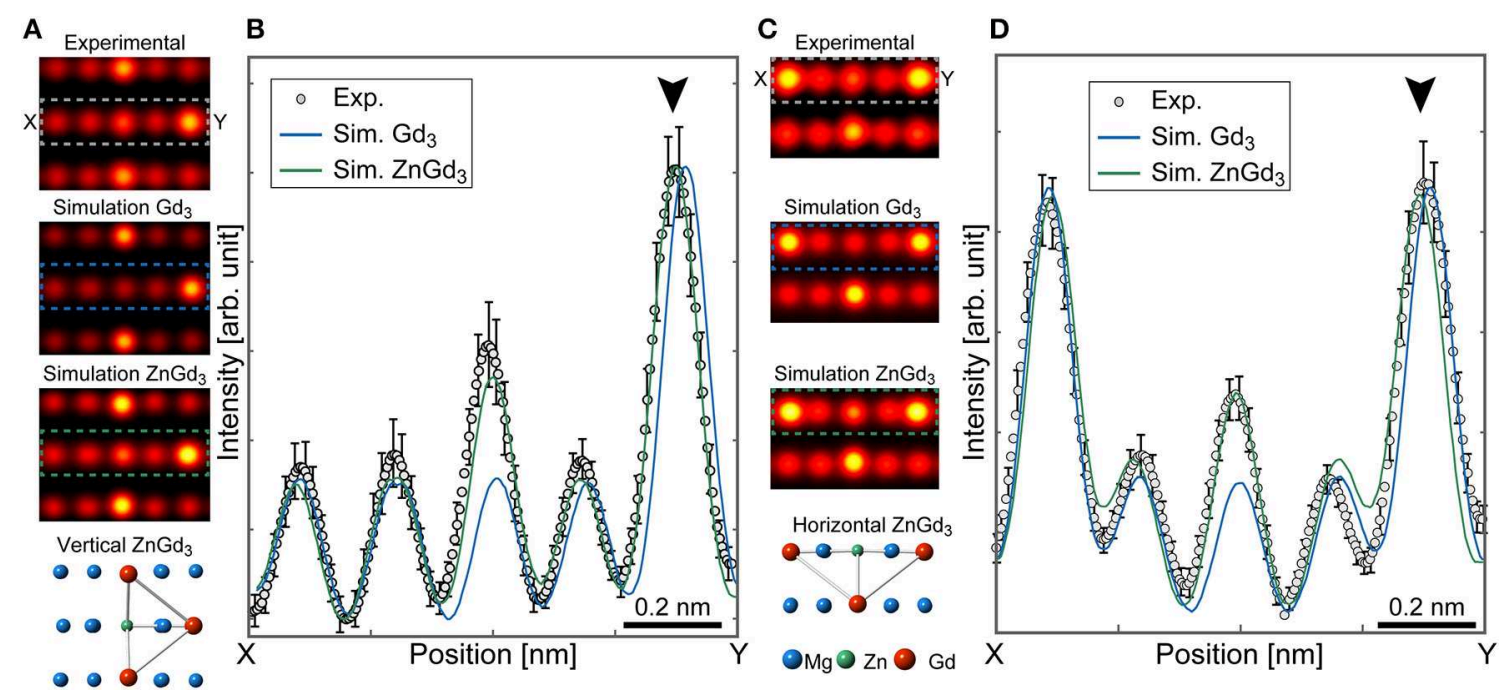

FIGURE 6 | (A) Experimental and simulated STEM images of the TV-SRO cluster. The experimental image has been reconstructed by averaging over the 26 local images in Figure 1d, by automatically selecting the similar contrast regions according to the autocorrelation search. Image simulations are performed for the $T_{V}$-SRO cluster with and without $\mathrm{Zn}$ atom, and the TV-SRO clusters are placed at the $4 \mathrm{~nm}$ in depth from the surface of the supercell. The conditions for simulations are the same as those described in Figure 2B. (B) Intensity profiles across $X-Y$ in the dotted rectangles in the images in (A). (C) Experimental and simulated STEM images of the $\mathrm{T}_{\mathrm{H}}$-SRO cluster. The 23 local images have been extracted and used for the reconstruction of the experimental image, and the averaging procedure and the simulation conditions are the same as those described in (A). (D) Intensity profiles across X-Y in the dotted rectangles in the images in (A).
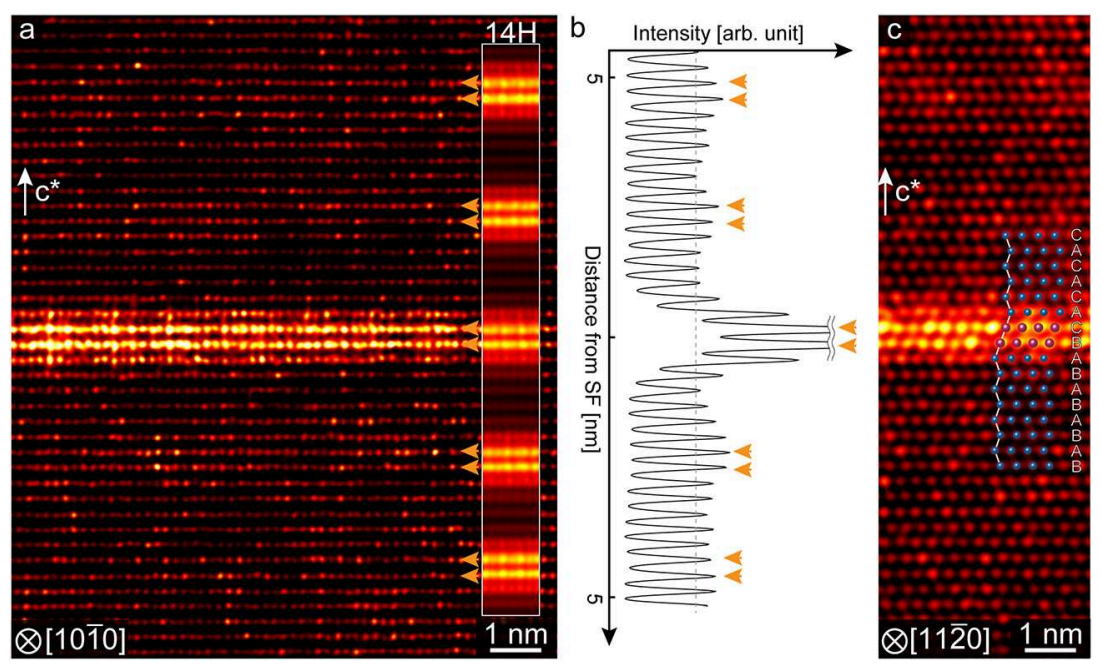

FIGURE 7 | (a) Atomic-resolution HAADF-STEM image of the $\alpha$-Mg matrix with a single SESF, taken along the [10 $\overline{10}]_{\text {hcp }}$ direction. $\mathrm{C}^{*}$ denotes the $c$-axis of the hcp crystal. A part of the 14H-type LPSO structure image is inserted for comparison, where the ordered arrays of the SESF are seen clearly. (b) Intensity profile of the entire image of (a) along the $c$-axis direction, in which weak intensity maxima are indicated by arrowheads. (c) HAADF-STEM image of the $\alpha$-Mg matrix with a single SESF, taken along the $[1 \overline{2} 10]_{\text {hcp }}$ direction. Stacking sequences are unambiguously identified, as shown by the schematic model inserted.

might be interpreted by solute interactions with the multiple $\mathrm{L} 1_{2}$-type clusters embedded within the SESF, the details of which will be described elsewhere.

\section{CONCLUSION}

In the present study, we have investigated the possible SRO clusters of solute $\mathrm{Zn}$ and $\mathrm{Gd}$ atoms formed in the annealed
$\mathrm{Mg}_{97} \mathrm{Zn}_{1} \mathrm{Gd}_{2}$ alloy, based on aberration-corrected HAADFSTEM observations. The SRO structures have been successfully determined with the aid of STEM image simulations and first-principles calculations. The main results are summarized as follows.

1. HAADF-STEM imaging has confirmed presence of the solute-atom SRO clusters in the $\alpha-\mathrm{Mg}$ phase as well as the LPSO phase. Quantitative image analyses with the aid of 
simulations show that the observed intensity variations indeed reflect single Gd atom distributions. Characteristic SROrelated contrasts have been directly extracted from the image, emerging characteristic SRO configurations composed of three Gd atoms; vertical and horizontal trimers.

2. First-principles calculations have shown that the energetically-favored SRO configurations are the two types $\mathrm{Gd}$ trimer, which are represented as $\mathrm{T}_{\mathrm{V}}$ - and $\mathrm{T}_{\mathrm{H}}-\mathrm{SRO}$ clusters and in good accordance with the STEM observations. Comprehensive investigations on possible $\mathrm{Zn}$ sites within the Gd-trimer clusters have shown that the $\mathrm{Zn}$ atoms are essentially involved both in the $\mathrm{T}_{\mathrm{V}}$ - and $\mathrm{T}_{\mathrm{H}}$-SRO Gd clusters; $\mathrm{D}_{19}$-like $\mathrm{ZnGd}_{3}$ clusters have emerged as significantly energy-stabilized configurations.

3. It has been found that the $\mathrm{D}_{19}$-like $\mathrm{ZnGd}_{3}$ clusters seem to form weak layered-atmosphere around the isolated SESF. This may imply that, during the transformation from the $h c p-\mathrm{Mg}$ to the LPSO structure, the composition modulations along the $c$-axis take place prior to the introduction of the $I_{2}$-SFs.

\section{REFERENCES}

Abe, E., Kawamura, Y., Hayashi, K., and Inoue, A. (2002). Long-period ordered structure in a high-strength nanocrystalline $\mathrm{Mg}-1$ at $\% \mathrm{Zn}-2$ at\% $\mathrm{Y}$ alloy studied by atomic-resolution Z-contrast STEM. Acta Mater. 50, 3845-3857. doi: 10.1016/S1359-6454(02)00191-X

Abe, E., Ono, A., Itoi, T., Yamasaki, M., and Kawamura, Y. (2011). Polytypes of long-period stacking structures synchronized with chemical order in a dilute Mg-Zn-Y alloy. Philos. Magazine Lett. 91, 690-696. doi: 10.1080/09500839.2011.609149

Egami, M., and Abe, E. (2015). Structure of a novel Mg-rich complex compound in Mg-Co-Y ternary alloys. Scripta Mater. 98, 64-67. doi: 10.1016/j.scriptamat.2014.11.013

Egusa, D., and Abe, E. (2012). The structure of long period stacking/order Mg-ZnRE phases with extended non-stoichiometry ranges. Acta Mater. 60, 166-178. doi: 10.1016/j.actamat.2011.09.030

Egusa, D., Yamasaki, M., Kawamura, Y., and Abe, E. (2013). Micro-kinking of the long-period stacking/order (LPSO) phase in a hot-extruded Mg97Zn1Y2 alloy. Mater. Transac. 54, 698-702. doi: 10.2320/matertrans.MI201216

Fujita, N., Matsushita, M., Tsukamoto, R., Yamasaki, M., Kawamura, Y., Irifune, T., et al. (2018). The structure of a novel long-period superlattice phase in $\mathrm{Mg}_{97} \mathrm{Zn}_{1} \mathrm{Yb}_{2}$ alloys. Scripta Mater. 150, 78-81. doi: 10.1016/j.scriptamat.2018.02.043

Garcés, G., Máthis, K., Medina, J., Horváth, K., Drozdenko, D., Oñorbe, E., et al. (2018). Combination of in-situ diffraction experiments and acoustic emission testing to understand the compression behavior of $\mathrm{Mg}$ - $\mathrm{Y}-\mathrm{Zn}$ alloys containing LPSO phase under different loading conditions. Int. J. Plasticity 106, 107-128. doi: 10.1016/j.ijplas.2018.03.004

Gröbner, J., Kozlov, A., Fang, X.-Y., Zhu, S., Nie, J.-F., Gibson, M. A., et al. (2015). Phase equilibria and transformations in ternary $\mathrm{Mg}-$ Gd-Zn alloys. Acta Mater. 90, 400-416. doi: 10.1016/j.actamat.2015. 02.044

Gu, X.-F., Furuhara, T., Chen, L., and Yang, P. (2018). Study on the planar segregation of solute atoms in Mg-Al-Gd alloy. Scripta Mater. 150, 45-49. doi: 10.1016/j.scriptamat.2018.02.041

Hagihara, K., Kinoshita, A., Sugino, Y., Yamasaki, M., Kawamura, Y., Yasuda, H. Y., et al. (2010). Effect of long-period stacking ordered phase on mechanical properties of Mg97Zn1Y2 extruded alloy. Acta Mater. 58, 6282-6293. doi: 10.1016/j.actamat.2010.07.050

Hagihara, K., Li, Z., Yamasaki, M., Kawamura, Y., and Nakano, T. (2019). Strengthening mechanisms acting in extruded Mg-based long-period

\section{DATA AVAILABILITY STATEMENT}

All datasets generated for this study are included in the article/supplementary material.

\section{AUTHOR CONTRIBUTIONS}

EA initiated and designed the research and interpreted the data. DE and KK preformed the experiments, analyzed the data, and carried out computer simulations. DE and EA wrote the paper.

\section{FUNDING}

This study was supported by JSPS KAKENHI for Scientific Research on Innovative Areas Materials Science of a Mille-feuille Structure (Grant Numbers JP18H05475, JP18H05479), and Nanotechnology Platform of the MEXT, Japan. stacking ordered (LPSO)-phase alloys. Acta Mater. 163, 226-239. doi: 10.1016/j.actamat.2018.10.016

He, S. M., Zeng, X. Q., Peng, L. M., Gao, X., Nie, J. F., and Ding, W. J. (2006). Precipitation in a $\mathrm{Mg}-10 \mathrm{Gd}-3 \mathrm{Y}-0.4 \mathrm{Zr}$ (wt.\%) alloy during isothermal ageing at $250^{\circ}$ C. J. Alloys Compd. 421, 309-313. doi: 10.1016/j.jallcom.2005.11.046

Homma, T., Kunito, N., and Kamado, S. (2009). Fabrication of extraordinary high-strength magnesium alloy by hot extrusion. Scripta Mater. 61, 644-647. doi: $10.1016 /$ j.scriptamat.2009.06.003

Honma, T., Ohkubo, T., Hono, K., and Kamado, S. (2005). Chemistry of nanoscale precipitates in $\mathrm{Mg}-2.1 \mathrm{Gd}-0.6 \mathrm{Y}-0.2 \mathrm{Zr}$ (at.\%) alloy investigated by the atom probe technique. Mater. Sci. Eng. A 395, 301-306. doi: 10.1016/j.msea.2004.12.035

Honma, T., Ohkubo, T., Kamado, S., and Hono, K. (2007). Effect of Zn additions on the age-hardening of $\mathrm{Mg}-2.0 \mathrm{Gd}-1.2 \mathrm{Y}-0.2 \mathrm{Zr}$ alloys. Acta Mater. 55, 4137-4150. doi: 10.1016/j.actamat.2007.02.036

Hosokawa, S., Stellhorn, J., Paulus, B., Maruyama, K., Kobayashi, K., Okuda, H., et al. (2018). The seeds of $\mathrm{Zn}_{6} \mathrm{Y}_{8} \mathrm{Ll}_{2}$-type clusters in amorphous $\mathrm{Mg}_{85} \mathrm{Zn}_{6} \mathrm{Y}_{9}$ alloy investigated by photoemission spectroscopy. J. Alloy Compd. 764, 431-436. doi: 10.1016/j.jallcom.2018.06.012

Inamura, T. (2019). Geometry of kink microstructure analysed by rank-1 connection. Acta Mater. 173, 270-280. doi: 10.1016/j.actamat.2019.05.023

Ishizuka, K. (2002). A practical approach for STEM image simulation based on the FFT multislice method. Ultramicroscopy 90, 71-83. doi: 10.1016/S0304-3991(01)00145-0

Itoi, T., Seimiya, T., Kawamura, Y., and Hirohashi, M. (2004). Long period stacking structures observed in $\mathrm{Mg}_{97} \mathrm{Zn}_{1} \mathrm{Y}_{2}$ alloy. Scripta Mater. 51, 107-111. doi: $10.1016 /$ j.scriptamat.2004.04.003

Jono, Y., Yamasaki, M., and Kawamura, Y. (2013). Effect of LPSO phase-stimulated texture evolution on creep resistance of extruded $\mathrm{Mg}-\mathrm{Zn}-\mathrm{Gd}$ alloys. Mater. Transac. 54, 703-712. doi: 10.2320/matertrans.MI201218

Kawamura, Y., Hayashi, K., Inoue, A., and Masumoto, T. (2001). Rapidly solidified powder metallurgy $\mathrm{Mg}_{97} \mathrm{Zn}_{1} \mathrm{Y}_{2}$ alloys with excellent tensile yield strength above $600 \mathrm{MPa}$. Mater. Transac. 42, 1172-1176. doi: 10.2320 /matertrans.42.1172

Kawamura, Y., and Yamasaki, M. (2007). Formation and mechanical properties of $\mathrm{Mg}_{97} \mathrm{Zn}_{1} \mathrm{RE}_{2}$ alloys with long-period stacking ordered structure. Mater. Transac. 48, 2986-2992. doi: 10.2320/matertrans.MER20 07142

Kim, J., and Kawamura, Y. (2013). Influence of rare earth elements on microstructure and mechanical properties of $\mathrm{Mg}_{97} \mathrm{Zn}_{1} \mathrm{Y}_{1} \mathrm{RE}_{1}$ alloys. Mater. Sci. Eng. 573, 62-66. doi: 10.1016/j.msea.2012.12.087 
Kimizuka, H., Kurokawa, S., Yamaguchi, A., Sakai, A., and Ogata, S. (2014). Twodimensional ordering of solute nanoclusters at a close-packed stacking fault: modeling and experimental analysis. Sci. Rep. 4:7318. doi: 10.1038/srep07318

Kishida, K., Yokobayashi, H., and Inui, H. (2013). The most stable crystal structure and the formation processes of an order-disorder (OD) intermetallic phase in the Mg-Al-Gd ternary system. Philos. Magazine 93, 2826-2846. doi: 10.1080/14786435.2013.790566

Koizumi, T., Egami, M., Yamashita, K., and Abe, E. (2018). Platelet precipitate in an age-hardening Mg-Zn-Gd alloy. J. Alloy Compd. 752, 407-411. doi: 10.1016/j.jallcom.2018.04.136

Kresse, G., and Furthmüller, J. (1996). Efficiency of ab-initio total energy calculations for metals and semiconductors using a plane-wave basis set. Comput. Mater. Sci. 6, 15-50. doi: 10.1016/0927-0256(96)00008-0

Ma, S.-Y., Liu, L.-M., and Wang, S.-Q. (2013). The predominant role of Zn6Y9 cluster in the long period stacking order structures of $\mathrm{Mg}-\mathrm{Zn}-\mathrm{Y}$ alloys: a firstprinciples study. J. Mater. Sci. 48, 1407-1412. doi: 10.1007/s10853-012-6890-4

Malis, T., Cheng, S., and Egerton, R. (1988). EELS log-ratio technique for specimen-thickness measurement in the TEM. J. Electron. Micr. Tech. 8, 193-200. doi: 10.1002/jemt.1060080206

Matsushita, M., Ingai, R., Yamasaki, M., Shinmei, T., Kawamura, Y., Irifune, T., et al. (2016). A novel long-period superlattice phase in $\mathrm{Mg}_{97} \mathrm{Zn}_{1} \mathrm{Yb}_{2}$ alloys synthesized under high-pressure. Scripta Mater. 122, 45-49. doi: $10.1016 /$ j.scriptamat.2016.04.022

Mittal, A., and Mkhoyan, A. K. (2011). Limits in detecting an individual dopant atom embedded in a crystal. Ultramicroscopy 111, 1101-1110. doi: 10.1016/j.ultramic.2011.03.002

Nie, J.-F. (2012). Precipitation and hardening in magnesium alloys. Metal. Mater. Trans. A 43, 3891-3939. doi: 10.1007/s11661-012-1217-2

Nie, J. F., Oh-ishi, K., Gao, X., and Hono, K. (2008). Solute segregation and precipitation in a creep-resistant Mg-Gd-Zn alloy. Acta Mater. 56, 6061-6076. doi: 10.1016/j.actamat.2008.08.025

Nishijima, M., and Hiraga, K. (2007). Structural changes of precipitates in an Mg5 at\%Gd alloy studied by transmission electron microscopy. Mater. Trans. 48, 10-15. doi: 10.2320/matertrans.48.10

Nishijima, M., Hiraga, K., Yamasaki, M., and Kawamura, Y. (2008). The structure of guinier-preston zones in an $\mathrm{Mg}-2$ at $\% \mathrm{Gd}-1$ at $\% \mathrm{Zn}$ alloy studied by transmission electron microscopy. Mater. Trans. 49, 227-229. doi: 10.2320/matertrans.MEP2007257

Nishioka, T., Yamamoto, Y., Kimura, K., Hagihara, K., Izuno, H., Happo, N., et al. (2018). In-plane positional correlations among dopants in $10 \mathrm{H}$ type long period stacking ordered $\mathrm{Mg}_{75} \mathrm{Zn}_{10} \mathrm{Y}_{15}$ alloy studied by X-ray fluorescence holography. Materialia 3, 256-259. doi: 10.1016/j.mtla.2018.09.002

Okuda, H., Yamasaki, M., and Kawamura, Y. (2017). Transition to long period stacking ordered structures in $\mathrm{Mg}_{85} \mathrm{Gd}_{9} \mathrm{Zn}_{6}$ alloys from amorphous ribbons examined by synchrotron radiation scattering: comparison with Mg85Y9Zn6 alloys. Scripta Mater. 139, 26-29. doi: 10.1016/j.scriptamat.2017.06.013

Okuda, H., Yamasaki, M., Kawamura, Y., Tabuchi, M., and Kimizuka, H. (2015). Nanoclusters first: a hierarchical phase transformation in a novel Mg alloy. Sci. Rep. 5:14186. doi: 10.1038/srep14186

Perdew, J., Chevary, J., Vosko, S., Jackson, K., Pederson, M., Singh, D., et al. (1992). Atoms, molecules, solids, and surfaces: applications of the generalized gradient approximation for exchange and correlation. Phys. Rev. B 46, 6671-6687. doi: 10.1103/PhysRevB.46.6671

Pollock, T. M. (2010). Weight loss with magnesium alloys. Science 328, 986-987. doi: $10.1126 /$ science. 1182848

Saal, J. E., and Wolverton, C. (2014). Thermodynamic stability of Mg-based ternary long-period stacking ordered structures. Acta Mater. 68, 325-338. doi: 10.1016/j.actamat.2013.10.055

Saito, K., Yasuhara, A., and Hiraga, K. (2011). Microstructural changes of GuinierPreston zones in an $\mathrm{Mg}-1.5 \mathrm{at} \% \mathrm{Gd}-1$ at\% $\mathrm{Zn}$ alloy studied by HAADF-
STEM technique. J. Alloys Compd. 509, 2031-2038. doi: 10.1016/j.jallcom.2010. 10.129

Sandlöbes, S., Pei, Z., Friák, M., Zhu, L.-F., Wang, F., Zaefferer, S., et al. (2014). Ductility improvement of $\mathrm{Mg}$ alloys by solid solution: $\mathrm{Ab}$ initio modeling, synthesis and mechanical properties. Acta Mater. 70, 92-104. doi: 10.1016/j.actamat.2014.02.011

Shao, X. H., Yang, Z. Q., and Ma, X. L. (2010). Strengthening and toughening mechanisms in $\mathrm{Mg}-\mathrm{Zn}-\mathrm{Y}$ alloy with a long period stacking ordered structure. Acta Mater. 58, 4760-4771. doi: 10.1016/j.actamat.2010.05.012

Umebayashi, T., Iikubo, S., and Ohtani, H. (2014). Thermodynamic analysis on a segregation behavior of alloying elements to stacking faults in $\mathrm{Mg}$ Y-Zn based LPSO structures. J. Jpn. Inst. Metals Mater. 78, 117-125. doi: 10.2320/jinstmet.JBW201307

$\mathrm{Xu}$, C., Zheng, M., Xu, S., Wu, K., Wang, E., Fan, G., et al. (2015). Improving strength and ductility of $\mathrm{Mg}-\mathrm{Gd}-\mathrm{Y}-\mathrm{Zn}-\mathrm{Zr}$ alloy simultaneously via extrusion, hot rolling and ageing. Mater. Sci. Eng. A 643, 137-141. doi: 10.1016/j.msea.2015.07.032

Yamamoto, Y., Sakamoto, Y., Masaki, Y., and Nishitani, S. R. (2013). First principles calculations of solute ordering in $\mathrm{Mg}-\mathrm{Zn}-\mathrm{Y}$ alloys. Mater. Trans. 54, 656-660. doi: 10.2320/matertrans.MI201207

Yamasaki, M., Anan, T., Yoshimoto, S., and Kawamura, Y. (2005). Mechanical properties of warm-extruded $\mathrm{Mg}-\mathrm{Zn}-\mathrm{Gd}$ alloy with coherent $14 \mathrm{H}$ long periodic stacking ordered structure precipitate. Scripta Mater. 53, 799-803. doi: 10.1016/j.scriptamat.2005.06.006

Yamasaki, M., Hagihara, K., Inoue, S., Hadorn, J., and Kawamura, Y. (2013). Crystallographic classification of kink bands in an extruded $\mathrm{Mg}-\mathrm{Zn}-\mathrm{Y}$ alloy using intragranular misorientation axis analysis. Acta Mater. 61, 2065-2076. doi: 10.1016/j.actamat.2012.12.026

Yamasaki, M., Matsushita, M., Hagihara, K., Izuno, H., Abe, E., and Kawamura, Y. (2014). Highly ordered 10H-type long-period stacking order phase in a Mg-Zn-Y ternary alloy. Scripta Mater. 78, 13-16. doi: 10.1016/j.scriptamat.2014.01.013

Yamasaki, M., Sasaki, M., Nishijima, M., Hiraga, K., and Kawamura, Y. (2007). Formation of $14 \mathrm{H}$ long period stacking ordered structure and profuse stacking faults in $\mathrm{Mg}-\mathrm{Zn}-\mathrm{Gd}$ alloys during isothermal aging at high temperature. Acta Mater. 55, 6798-6805. doi: 10.1016/j.actamat.2007. 08.033

Yamashita, K., Itoi, T., Yamasaki, M., Kawamura, Y., and Abe, E. (2019). A novel long-period stacking/order structure in Mg-Ni-Y alloys. J. Alloy Compd. 788, 277-282. doi: 10.1016/j.jallcom.2019.02.219

Yokobayashi, H., Kishida, K., Inui, H., Yamasaki, M., and Kawamura, Y. (2011). Enrichment of $\mathrm{Gd}$ and $\mathrm{Al}$ atoms in the quadruple close packed planes and their in-plane long-range ordering in the long period stackingordered phase in the Mg-Al-Gd system. Acta Mater. 59, 7287-7299. doi: 10.1016/j.actamat.2011.08.011

Zhu, Y. M., Morton, A. J., and Nie, J. F. (2010). The 18R and $14 \mathrm{H}$ long-period stacking ordered structures in Mg-Y-Zn alloys. Acta Mater. 58, 2936-2947. doi: 10.1016/j.actamat.2010.01.022

Conflict of Interest: The authors declare that the research was conducted in the absence of any commercial or financial relationships that could be construed as a potential conflict of interest.

Copyright (c) 2019 Egusa, Kawaguchi and Abe. This is an open-access article distributed under the terms of the Creative Commons Attribution License (CC BY). The use, distribution or reproduction in other forums is permitted, provided the original author(s) and the copyright owner(s) are credited and that the original publication in this journal is cited, in accordance with accepted academic practice. No use, distribution or reproduction is permitted which does not comply with these terms. 